\title{
Corporate University Theory and Practice: the Case of Platt University, USA
}

\author{
Gary Ewer, Platt Electrical Supply, USA \\ Darlene Russ-Eft, Oregon State University, USA
}

\begin{abstract}
Corporate universities (CUs) have been in existence in the United States since the early 1900s. There is, however, little empirical research on these types of organizations. This study focused on identifying the operational factors of an existing electrical wholesale distributor's corporate university, using a previously described theoretical model. The major research question was: What are the operational factors associated with this particular CU?
\end{abstract}

Applying a bounded case-study approach, data were collected from 62 in-person interviews with executives, employees and vendors; classroom observations; and reviews of available documents. Trustworthiness was ensured by using triangulation, member checking, and expert peer review.

Results revealed some consistency with the theoretical model; however, a new profile and new factors were identified. These included: (a) new profile of leaders-as-teachers, and five new factors: (b) partnerships with vendors, (c) partnerships with outside organizations, (d) use of course prerequisites, (e) time for required training, and (f) the integrated systems model.

The results of this study may assist other HRD practitioners and CU Directors in making informed decisions concerning their workplace training efforts, specifically regarding the use of leaders as teachers and the strategic role that can be played by a CU in creating a competitive advantage in the workplace. In addition, suggestions for future research are provided.

Key Words: corporate universities, human resource development, training, learning

\section{Introduction}

Platt Electric Supply, has successfully developed both a learning and teaching organization through their use of a corporate university (CU) which in turn has provided a competitive advantage for the company. Platt University has become a valuable business partner by helping the workforce learn important business skills as well as improved product knowledge that leads to increased sales. Business leaders recognize that work and learning have become the same thing (Meister, 1998). To ensure continued growth in workforce development, progressive companies have established corporate universities (CUs). Prince and Stewart (2002) described the corporate university's role as supporting the organization's learning and knowledge creation process. Corporate universities strategically direct organizational change by facilitating the knowledge management process as well as by controlling the learning agenda (Prince \& Beaver, 2002). Unfortunately, few empirical research studies have been undertaken concerning the operation of corporate universities (Blass, 2001; Taylor, 2003; Taylor \& Paton, 2002).

Industry as educator is not a new concept. Early in United States' history, no formal education system existed to develop the emerging workforce. Out of necessity, American industries became employer and educator of the workforce (Miller, 1996). Today, competitive pressures and 
technological advances require that modern corporations increasingly become chief educators to the workforce (Lipp, 2013; Meister, 1998).

The purpose of this case study was to examine a specific electrical wholesale distributor's corporate university using an available conceptual framework for defining and classifying corporate university operations. The study was conducted by both a workplace practitioner and an HRD academic scholar. It addressed the following question:

- What are the operational factors associated with this particular CU?

\section{Literature Review}

The purpose of this literature review was to gather and evaluate the most current academic research on corporate universities, including the developmental history of CUs, and how CUs effectively manage workforce development. Online resources at the Valley Library at Oregon State University were used to access full text electronic journals. These included Advances in Developing Human Resources, Community College Review, Human Resource Development International, Human Resource Development Quarterly, Journal of Industrial and Commercial Training, Journal of European Industrial Training, Journal of Workplace Learning, The Internet and Higher Education Journal, and the Educational Resource Information Center (ERIC). A key word search was used including such phrases as: business training, company training programmes, corporate university, knowledge management, organizational learning, and workplace development.

\section{History of $\mathrm{CUS}$}

One of the earliest examples of a factory school in the United States was in 1872 when Hoe \& Company of New York established a training programme to help workers gain new skills to improve the assembly of printing presses (Miller, 1996). In 1913, an "Industry Association Support" meeting was held at New York University and resulted in formation of the "National Association of Corporation Schools". This association represented 34 corporations and later became known as the American Management Association (AMA) (Beatty, 1918).

One of the earliest workplace training institutions to use the word "university" was developed by Goodyear Tire and Rubber Company (Allen, 1949). Goodyear's Industrial University was established in 1913 to address the training and development needs of its 35,000 employees. Within seven years the Goodyear programme had grown to four different schools (a) production, (b) sales, (c) commerce, and (d) household arts and had taken on the mantle of Goodyear University (University and Factory, 1920). This New York Times article stated that Goodyear University employed 110 teachers with an enrollment of 6,000 employee participants. Identification of Goodyear's University is a possible addition to academic literature, as it has not been cited or mentioned with early CUs in the United States.

The first CU cited by most scholars is General Electric's Management Institute of Crotonville, New York in 1955 (El-Tannir, 2002; Freifeld, 2008; Gerbman, 2000; Meister, 1998; Veldsman, 2004). Freifeld (2008) stated that the goal of the GE programme was to develop a succession planning process that would educate GE's emerging leaders. GE's leadership programme is still in operation today and is a model within the industry. In 1963, Walt Disney created Disney 
University in Anaheim, California to ensure that all new employees understood and delivered the service he envisioned (Lipp, 2013). The most cited example of a corporate university is McDonald's Hamburger U. Opening in 1963, this CU claims to be the nation's number one trainer, even larger than the United States Army for size and scope, training employees in 65 countries (Meister, 1998).

Internationally there are four predominant associations for Corporate Universities they are: (a) CorpU, (b) The Corporate University Enterprise, (CUE), and (c) The Global Association of Corporate Universities and Academies, (G-AUCA), and (d) The Global Council of Corporate Universities, (Global CCU). CorpU and The Corporate University Exchange are located in the United States and the Global Association of Corporate Universities and Academies (G-ACUA), and the Global Council of Corporate Universities, (Global CCU) are located in Western Europe.

Corporate universities have received a great deal of scholarly criticism. In an attempt to increase the status of their training departments, some business leaders have glibly added the word "university" to the nameplate (Greenberg, 1998). Some who work in a traditional university setting find it hard to endorse the concept of a corporate university (Craig, Clarke, \& Amernic, 1999). Blass (2001) stated that the corporations' adoption of the title "university" has "dumbed down" the term, making it acceptable for the term to be used in a variety of inappropriate ways (p.15). This challenges the appropriateness of corporate bodies adopting the term "university".

In defense of the term "corporate university" Wills (2001) suggested that corporations who use the term "university" are attempting to gain a positive association with a learning environment. She further stated that corporations do produce new knowledge in the form of research and development. Finally, Wills suggested that the use of academic terms by CUs will continue to grow as partnerships with higher education increase. Furthermore, a CU can represent a way to incorporate strategic HRD into the organization (Herd \& Alagaraja, 2016).

\section{Empirical studies of $\mathrm{CUs}$}

This section will review empirical studies concerning CU operations. It will describe CU characteristics and some evaluations of CUs. Finally, a model that integrates CU operational characteristics and effects will be presented.

CU operations. Walton (2005) conducted a comparative analysis of similarities and differences between traditional universities (TUs) and CUs in the US and the UK. The study found little commonality in TU and CU focus. Learning within TUs was associated with scholarly activity, teaching, and research. Learning within CUs was associated with training, continuous improvement, and competitive advantage. This was confirmed by El-Tannir (2002), whose study of three CUs showed them to provide a continuous learning process. Later, Allen (2010) examined current practices of CUs worldwide. This study showed that CUs are designed to expand organizational capabilities by using learning as a strategic lever. Indeed, Prince and Stewart (2002) suggested that CU success in the future will rely more on managing complex interactions of organizational learning subsystems and less on managing training programmes.

CU differences from training departments and traditional universities. One of the many ways a corporate university is distinguished from a training department is the breadth of audiences that it serves, including employees, customers, vendors, and communities (Meister, 1998). Gerbman (2000) stated that traditional training programmes are more reactive while CU programmes are 
more proactive. Walton (2005) asserted that the traditional university has become progressively more corporate in their outlook, while corporations are becoming more knowledge-based in their viewpoint.

Veldsman (2004) identified 21 differences between a training department, corporate university, and a traditional university. This research provided concrete examples of the unique focus that CUs yield in the workplace. His research revealed several generalizations that training departments tend to focus on the organization's operational needs; corporate universities tend to focus on the organization's business needs; and finally, traditional universities tend to focus on the broader educational needs of society.

Finally, Kiely (2007) stated that it is time to recognize that corporate universities are very different from traditional training departments. Training departments focus their efforts on training employees. In contrast, corporate universities focus on supporting the organization's strategy, which may include more than simply training. Paton, Peters, Storey, and Taylor (2005) described a CU as a strategic learning initiative that is (a) wholly owned by the parent organization, (b) with the primary focus of providing learning opportunities for employees, suppliers, and customers of the parent organization and, (c) utilizing the symbols and language of higher education to promote an atmosphere of learning.

\section{A model of CU operational factors}

Several CU models were reviewed before selecting Abel's (2008) taxonomy for defining and classifying a Corporate University to guide this present study, and these are briefly described here. Dealtry (2002) provided a framework for strategic selection of CU functions, while Prince and Stewart (2002) identified four essential processes that together constitute the key elements of the corporate university's learning subsystem. These included: (a) knowledge system and process, (b) networks and partnerships, (c) learning process, and (d) people process. Veldsman (2004) discussed four learning domains of a CU: (a) strategy development/implementation, (b) operational delivery enhancement, (c) constructive organizational dynamics, and (d) personal development. Finally, Wheeler and Clegg (2005) identified four different models for CUs. These are (a) centralized model where learning is directed by a single department. (b) decentralized model with no central control, (c) federated model with strong central control that ties together all disparate training efforts across the organization, and (d) the hybrid model where the organization could provide central control in the organization's home country but then be decentralized internationally.

The authors selected Abel's (2008) theoretical model as it addressed factors described in other CU models. In addition, Abel's model was developed through data gathered from a significant sample size of 210 CUs operating in North America as well as being the most current CU model. Findings revealed four key profiles of a corporate university based on factor analysis. These profiles were: organizational profile, operational profile, learning delivery profile, and partnership profile (See Figure 1). Abel stated that the framework would act as a "checklist" to help evaluate and enhance practitioners' understandings of different types of CUs and their operations.

\section{Methods}

The authors chose a qualitative case-study approach for this research project. The case study method (Yin, 2009) enabled researchers to examine first-hand operations of this CU and interact 
directly with participants. In addition, Patten (2009) described qualitative non-experimental studies as allowing researchers to observe participants and then describe what they saw in the natural setting. Such a method requires the gathering of multiple forms of data, such as interviews, focus groups, observations, in order to develop a thorough picture of the case and to provide triangulation or corroboration of the findings from one method.

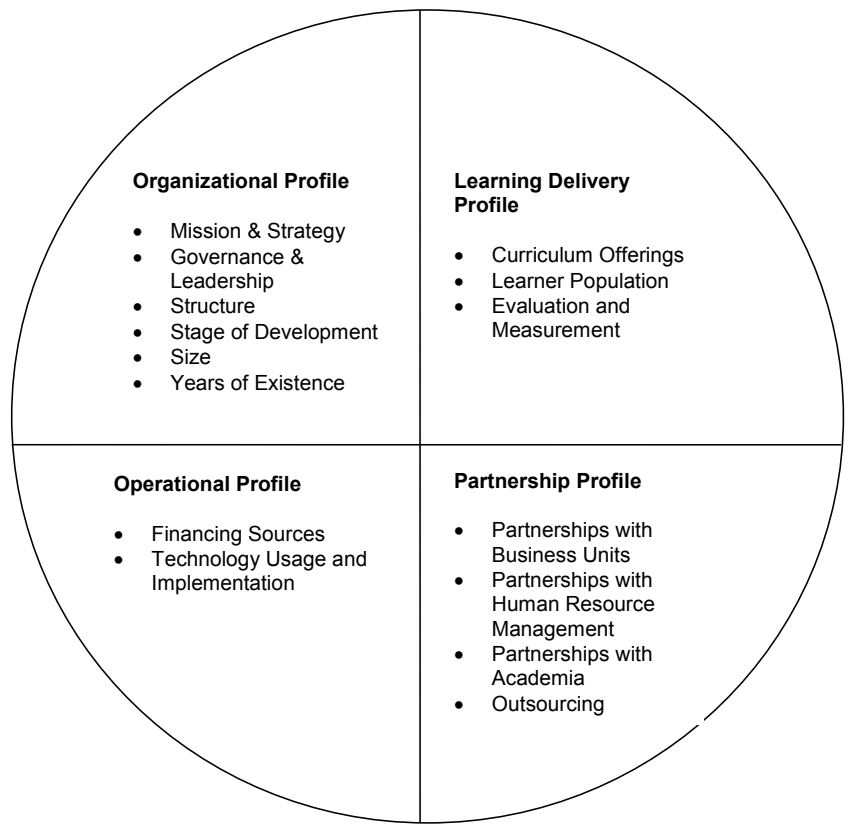

Figure 1: Abel's Conceptual Framework for Defining and Classifying Corporate Universities (Used with permission)

\section{Data collection}

The study thoroughly examined: (a) study site, (b) study participants, (c) interview results, (d) observational results, (e) organizational documents, and (f) artifacts. The first author is the director of this CU, while the second author is an academician. This collaboration facilitated the examination of this CU within the framework of available research on CUs. Because of concerns regarding conflict of interest, an independent researcher conducted in-person data collection.

Study site. Platt University serves as a central training facility for Platt Electric Supply an electrical distributor with 1240 employees in 123 branch locations in the Western United States. The CU uses a blended approach to learning with 50\% classroom delivery and $50 \%$ online training delivery. In 2012, the company was purchased by Rexel a global electrical distributor headquartered in Paris France. The primary classroom observation research site was at Platt Electric Supply, located in Beaverton, Oregon. Additional employee interviews were held at selected branch locations in the greater Portland Oregon area.

Study participants. Participants consisted of two groups: (a) company employees, including officers, department heads, branch managers, and front-line workers and (b) outsourced vendors, including a sales training consultant, community college administrator, and an LMS (learning 
management system) national account manager. Company employees were directly observed in two classroom settings and interviewed by the independent researcher. The three outsourced vendors were also interviewed by the independent researcher.

Direct observation. Two direct observations were conducted by the independent researcher over a two-day period. The first class had 20 employee participants and four employee instructors, and the second class had 16 employee participants and four employee instructors. Each class observation lasted eight hours. An observation checklist was used by the independent researcher to gather specific information on behaviors.

Interviews. Interviews used a combination of random sampling for selecting employees and purposive sampling methods for selecting governing board members and vendors. The 18 interviews were conducted by the independent researcher and were audio recorded in order to ensure accuracy in understanding. Following removal of identifying information and use of pseudonyms in place of participant names ( $G$ names for governing board members, $E$ names for employees, and V names for vendors), interviews were sent to the first author for analysis.

Documents and artifacts. Published company documents were thoroughly reviewed. Artifacts specifically related to the organization's learning culture were gathered to provide social and cultural context. These included the company's mission and strategies, the CU's mission and strategies and a training development matrix.

\section{Data analysis procedures}

The first author organized data, assigned codes, and developed 36 possible themes from over 1400 interview comments. Triangulation was achieved through comparison of the interviews, documents, and artifacts. Member-checking took place by having interviewers review and affirm the interview contents. Finally, an external audit was completed with an outside researcher.

\section{Results}

Three themes emerged:

- Theme 1: Factors consistent with Abel's (2008) conceptual framework for defining CUs.

- Theme 2: Factors not consistent with Abel's conceptual framework for defining CUs.

- Theme 3: New factors and profiles.

Evidence is presented demonstrating that this particular CU had a linkage to each of Abel's four profiles and 15 operational factors. One new profile and five new operational factors were identified that were not originally in Abel's conceptual framework. Note that we used the term "theme" to identify our three categories of results, and we used Abel's terms of "profiles" and "factors" to discuss those results.

\section{Theme 1: Factors consistent with Abel's conceptual framework for defining CUs}

This study confirmed that all four profiles of Abel's framework were evident in the CU studied. This theme will be discussed in the four profiles in Abel's (2008) conceptual framework: (a) organizational, (b) operational, (c) learning delivery, and (d) partnership. 
Organizational profile. This CU has been in operation for more than 27 years. It represents a well-established, well recognized, and inclusive 'function' within the business. Platt University provides the framework for learning throughout the organization. Respondents' comments included, for example:

... truly [Platt] is a culture of learning ... there are training programmes that are available to everyone.

(Valerie, Company Vendor)

it [Platt University] energizes our people, and it's a big reason for our success. (Greg, Governing Board Member)

The CU occupies a distinct, largely autonomous, positioning within the organization. The governing board is made up of four leadership roles (a) President/CEO, (b) VP of Human Resources, (c) VP of Marketing, (d) and Director of Education; and it determines the CU's goals, objectives, and strategy. The Platt University mission is to develop its people. Six strategies are supportive of this mission. They are:

(a) Advance the company culture, values, and global priorities of Platt and Rexel.

(b) Inspire lifelong learning.

(c) Build a leadership bench of managers and teachers.

(d) Increase product knowledge - we sell what we know.

(e) Develop effective selling skills.

(f) Improve operational knowledge.

The "Platt University Organizational Chart - 2015" listed two full-time educational staff members, one in the role of "Director of Education" and one in the role of "Instructional Designer". This document also revealed that approximately 40 company leaders, who held roles of Officers, Department Heads, Division Managers, Sales Managers, and Branch Managers volunteered to teach in the $\mathrm{CU}$ on a part-time schedule.

This CU is located within the corporate headquarters building, as described in "Platt University Organizational Chart - 2015". The CU reports to the governing board. Its members provided helpful responses concerning centralization of CU operations and its impact. Garrett (Governing Board Member) said, "Platt University is the one thing that really binds us together".

Operational profile. A portion of funding for this particular CU is provided by vendors. This new operational factor is titled the "vendor funding model" and will be discussed in greater detail later.

Continual learning is an important value at Platt as $100 \%$ of the organization's population participates in the workplace learning process. Working directly with the executive team, the University's director plans for the development of employees to address future staffing needs. The "On-course Training Matrix" listed each branch role in ascending order from entry level warehouse position to advanced regional product specialist position. Both employees and supervisors used the On-Course Training Matrix as a framework to follow the employees' development process.

With entry level training, there are "training tracks for the first 90 days, the first 180 days, and the first 360 days that an employee is with us. It covers the basics" (Greg, Governing Board Member). Platt also has two leadership development programmes, LEAD and PACE. LEAD is 
an acronym for "Learn, Experience, Achieve, and Do". Upon successful completion of LEAD-2, graduates can apply to PACE, or "Platt, Accelerated, Career, Enhancement". The third strategy of the CU mission to advance company culture, values, and global priorities of Platt/Rexel is taught to new employees beginning on the first day of work.

Both reaction and testing take place as part of the evaluation process. As for behavior change on the job, Ed (Front-Line Worker) stated,

Participants ... have a two week assignment on what they have learned in class ... [helping] customers install the Platt App ...

Concerning level four results with impact, Ed stated,

[class participants] have ... a measurable task to either increase sales or increase customer service ...

Finally, for courses, Platt University has used the BlueVolt learning management system (LMS) since 2004 "to build, deliver, and track online courses" (Valerie, Company Vendor). The online course catalog includes leadership management, sales, product, safety, technical, and operational training.

Partnership profile. The CU works with line managers to determine requirements and design learning programmes. Instead of partnering with HR to develop a reward and recognition system, this CU partners with the Sales and Marketing department to recognize employee learning accomplishments. Valerie (Company Vendor) stated, "Branches track metrics using scorecards

...”. Sales and Marketing reviews training accomplishment and awards certificates to branches and departments for course completions and educational achievements.

This CU does not award college degrees, but it does award college credit for workplace training. A partnership with a local community college makes this awarding of credit possible. In addition, the CU has partnered with the community college to deliver credit programmes instead of noncredit programmes. One deciding factor for partnering with Clackamas Community College was their agreement to award college credit for Platt U courses. Although the CU has not partnered with universities for faculty exchange or development programmes, its instructors have been invited by local academic universities, community colleges, and high schools to be guest presenters.

This CU outsources one portion of its advanced BASE sales training programme to a professional sales trainer. At the same time, the $\mathrm{CU}$ has a full-time instructional designer who develops $80 \%$ of the online course content used in the workplace. Also, as previously mentioned, the LMS has been outsourced.

\section{Theme 2: Factors not consistent with Abel's conceptual framework for defining CUs}

This section will examine four areas of operations that this CU was not consistent with in Abel's (2008) conceptual framework. They are: (a) the sales revenue model, (b) partnerships with community colleges, (c) partnership with sales and marketing, and (d) the tuition reimbursement model.

Sales revenue model. Strong evidence was revealed from the interviews that this particular CU's training programme has helped make direct contributions to organizational selling efforts. 
"Platt U works with programme directors and vendors to create training on new products so we can sell them to our customers" (Elias, Front-Line Worker).

Partnerships with community colleges. Abel's (2008) academic partnership profile described CUs as forming partnerships with universities. However, this particular CU has formed a strategic partnership with Clackamas Community College.

We [Clackamas Community College] credential several Platt courses for the purpose of awarding college credit to their employees. ... Employees can earn from 1-3 college credits for completing Platt University workplace courses (Vanessa, Company Vendor).

This academic partnership allows Platt employees to earn up to 14 lower-division Professional/ Technical College credits at the 100 level and above.

Partnership with sales and marketing. In Abel's (2008) research, the Human Resources department was described as the one to partner most often with CUs in the development of a recognition system to promote employee learning accomplishments. However, this particular $\mathrm{CU}$ has partnered with the Sales and Marketing department to recognize employee learning accomplishments. Each month the Sales and Marketing department sends out report cards to each branch and department location. Garrett (Governing Board Member) indicated that, "All of us have report cards, and part of that is training with our vendors". Report cards list the mission, strategies, and goals achieved in business activities such as the number of active customers, number of new customers added, and percentage of order fill rates; furthermore, the last measurement is the number of courses completed during the month.

Tuition reimbursement model. Tuition reimbursement was not mentioned in Abel's (2008) profiles or factors. However, this $\mathrm{CU}$ has identified tuition reimbursement as a tactical expenditure within the employee development process and the tuition reimbursement is described in company documents as an employee benefit. The offer of tuition reimbursement is an important benefit to those being recruited as well as an important tool in retention efforts.

\section{Theme 3: New profiles and factors}

This section will examine one new profile and five new operational factors identified in this study when compared to Abel's (2008) conceptual framework. The one new profile is (a) the leaders-as-teachers profile. The five new operational factors are: (a) partnerships with vendors, (b) partnerships with outside organizations, (c) use of course prerequisites, (d) timing of required training and (e) the integrated systems model.

New profile: Leaders as teachers. This research project discovered a possible fifth profile, the Leaders-as-Teacher's profile. This fifth profile interacts naturally with the other four profiles and has demonstrated transformation of the original conceptual framework into a true learning system (Betoff, 2014).

The leaders-as-teachers concept was evidenced in the interview process. Greg (Governing Board Member) stated, "So all the leadership programme here is taught by Platt leaders, and they consider it an honor to be asked". Emily (Front-Line Worker) valued the opportunity because she gained helpful and practical knowledge, “... listening to our Instructor and their real-life situations ...". 
Since 1988, Platt University has successfully involved leaders-as-teachers and developed Platt Electric Supply into a learning organization. The company required that the CU not hire permanent teaching staff, but instead utilize company officers, department heads, division managers, sales managers, and branch managers in part-time teaching roles. This action strengthened the leadership development process at Platt.

"All leaders can and must be teachers" (DeSmet \& McAlpine, 2010: 2). Betof (2014) described the six key benefits of using the leaders-as-teachers approach: (a) helps drive results, (b) stimulates development of leaders and associates, (c) improves leadership skills of those who teach, (d) strengthens organizational culture and communications, (e) promotes positive organizational change, and (f) reduces cost by leveraging top talent. "Winning organizations use learning, teaching, coaching, and mentoring in ways that their competition does not" (p.38).

Factor 1: Partnerships with vendors. This is the first of five new operational factors identified in this study. Concerning CU funding models Abel (2008) described four types: (a) corporate budget model, (b) charge-backs to business unit's model, (c) pay for services model, and (d) self-funded Profit/Loss model. This CU operates using a combination of the "Corporate Budget" model, and a new "Vendor Funding" model, with the latter model not mentioned in any academic literature to date. In this model, vendors who sell products through the parent organization of the corporate university underwrite some course development costs for training delivered on the wholesaler's Learning Management System (LMS). This model benefits the vendor, the parent organization, and the organization's corporate university. In the vendor-funding model, vendors provide funding for course development and cash incentives to employees for learning about new products. Evan (Front-Line Worker) stated, "Platt awards Platt [Blue]bucks for learning about new products" This partnership has created a sustainable financing system that benefits both the organization and vendor.

Factor 2: Partnerships with outside organizations. This is the second of five new operational factors identified. As one example, Platt has partnered with Toastmasters International (2015) since 2008 to help learners improve public speaking and leadership skills. At Platt, participation in Toastmasters is required within leadership training programmes. Greg (Governing Board Member) stated, "We found that Toastmasters has been a wonderful programme for us".

Factor 3: Use of course prerequisites. Use of course prerequisites represents the third new operational factor. A course completion hierarchy or sequence was identified requiring participants to complete course prerequisites before advancing. Use of course prerequisites means that employees gain knowledge and experience necessary before moving to the next level of classes.

Factor 4: Adequate time for required training. This is the fourth of the new operational factors. The independent researcher received information from several managers and hourly workers that the amount of required training had increased, and some were struggling to finish during regular working hours. Eaton (Front-Line Worker) said, "It can take an individual four to five hours to do some of these [courses] and we don't have four to five hours to sit down to and do it [training] within the company time". Hourly, non-exempt employees, however, must complete these courses during their regular shift or in overtime, if approved. Salaried, exempt employees can complete required courses on their own time after regular work hours.

Factor 5: Integrated systems model. This is the final new operational factor. With the addition of the leaders-as-teachers profile and five operational factors, the $\mathrm{CU}$ framework now represents 
an integrated systems model (See Figure 2). This model connects the leaders-as-teachers profile, organizational profile, learning delivery profile, operational profile and, the partnership profile into an integrated system with inputs and outputs.

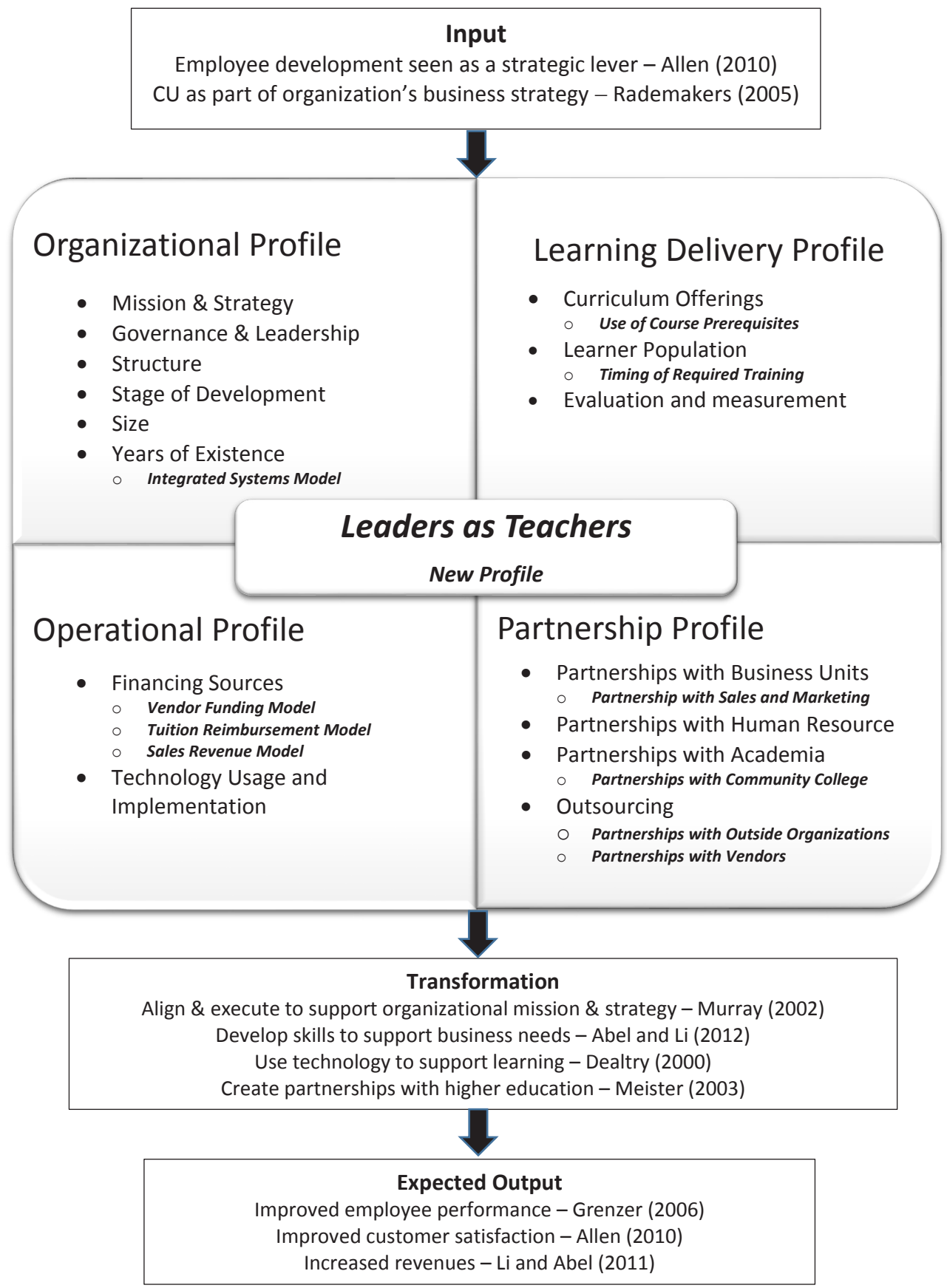

Figure 2: Conceptual Framework for Corporate Universities (Adapted with permission) 


\section{Conclusions}

The present study, involving a single in-depth case study of a corporate university within an electrical supply company, confirmed the Abel (2008) model. Figure 2 provides a model for the $\mathrm{CU}$ indicating that employee development is seen as a strategic lever. Furthermore, the CU is recognized as being able to implement that strategy and vision. The present study confirmed much of Abel's (2008) model. At the same time, it added an important profile, that of "leader as teacher". The profile is placed in the center, since it is critical to enabling and facilitating the other profiles. The figure also shows the addition of five new factors: (a) partnerships with vendors, (b) partnerships with outside organizations, (c) use of course prerequisites, (d) time for required training, and (e) the integrated systems model. Finally, the model suggests that the CU leads to a transformation: (a) align and execute to support the organization's mission and strategy, (b) develop employee skills to support business needs, (c) use technology to support learning, and (d) create partnerships with higher education institutions. This organizational transformation then leads to certain organizational outcomes: (a) improved employee performance, (b) improved customer satisfaction, and (c) increased revenues.

There are several limitations to this study. This organization has 123 locations in nine Western states; however, the study was limited to the greater Portland metropolitan area. It gathered a small sample of 18 interviews to represent 1,240 people. An additional limitation to the study was that the sample proved to be management heavy. It would be helpful to extend use of purposeful sampling to include a larger group of hourly employees. Finally the sample selection did not consider ethnicity, so it is not known how representative the interviews were concerning ethnic diversity of the company. Hearing from the growing diverse employee population would add important cultural and gender perspectives.

\section{Recommendations for further research}

Given the paucity of research on CUs, several questions remain concerning CUs, operation, and outcomes. Some questions include: (a) to what extent does the proposed model, with its additional profile and factors, operate in other existing CUs? (b) what portions of the model appear to be most important for CU success? (c) to what extent does the leaders as teachers approach exist in other CUs? and (d) how prevalent is the vendor-funding model?

\section{Implications for $C U$ practice}

The findings of this study point to several implications for addressing and improving CU operations. A CU, such as Platt University, that contributes to the organization's selling efforts becomes an important business partner. This aligns with Meister's (1998) suggestion for CU leaders as active business partners and suggests alignment with a move to strategic HRD. Furthermore, the focus on business strategy and support for that strategy helps to differentiate this CU and suggests an important approach for other CUs.

CUs may benefit from an educational partnership with a community or technical college to award credit for work related training. Awarding college credit for company sponsored training can be viewed as an important benefit by employees as well as help to improve the organization's recruitment and retention efforts. 
Rather than partnering only with HR, Platt University has instead partnered with sales and marketing to develop a recognition system and promote employee learning accomplishments. This partnership has created several benefits. Both employees and branches are recognized for courses completed. Employees can earn cash incentives for completing selected product courses. As a result, the CU has gained increased visibility and profitability by providing product and sales training that leads to increased revenue for the company, and it is now seen as a valuable and strategic business partner achieving significant training and business results. Again, such a practice helps to ensure an alignment of the $\mathrm{CU}$ with the organizations strategy, particularly with regard to revenues and profits.

The addition of the leaders-as-teachers profile provides an important new aspect to the CU model, and it represents an approach that can benefit other CUs. CU leaders who implement a leadersas-teachers profile in the future will find an important development tool for the growth of both leaders and learners within the organization. Leaders who teach are challenged to develop their communication and leadership skills, and they contribute by helping develop talent within the organization. Furthermore, these leaders become directly connected with the CU and contribute to the strategic emphasis of the CU. Employees benefit from the leaders-as-teachers process as they have opportunities to hear helpful workplace stories and learn practical work experiences that expand their understanding of the company mission, culture, and core values. Employees learn the importance of giving back to the organization, through teaching and sharing their own work experiences. Both authors feel that learning organizations can be sustainable when a leaders-as-teachers model is implemented within the organization.

Finally, CU leaders may find benefit by partnering with the product vendors represented within their organization. Platt University has product vendors who provide training materials, marketing materials, and financial support to help underwrite the development costs of product courses. Product vendors benefit as employees of the wholesaler or retailer complete training courses that enable the company to sell more products. Again, such actions connect the CU with the organizational strategy and can serve as a model for other CUs.

\section{References}

Abel, A. (2008). The development of a conceptual framework and taxonomy for defining and classifying corporate universities (Doctoral dissertation) ProQuest LLC Ann Arbor MI.

Allen, H. (1949). The house of Goodyear. Cleveland, OH: Corday \& Gross.

Allen, M. (2010). Corporate universities 2010: globalization and great sophistication. The Journal of International Management Studies, 5(1), 48-53.

Beatty, A. (1918) Corporation schools. Bloomington IL: Public Schools.

Betof, E. (2014). Leaders as teachers: Unlock the teaching potential of your company's best and brightest. Auburn Hills, MI: Data Reproductions Corporation (ASTD).

Blass, E. (2001). What's in a name?: A comparative study of the traditional public university and the corporate university. Human Resource Development International, 4(2), 153-172. doi: 10.1080/13678860121806

Craig. R., Clarke, F., \& Amernic, J. (1999). Scholarship in university business schools: Cardinal Newman, creeping corporatism and farewell to the distributor of peace? Accounting, Auditing and Accountability Journal, 12(5), 510-524. doi: 10.1108/09513579910298453 
Corporate University Enterprise (n.d.). Website. About CUE. Retrieved from http://www.cuenterprise. com/777about.php

CorpU (n.d). Website. About us. Retrieved from https://www.corpu.com/corpu/about/about-us/

DeSmet J., \& McAlpine, C. (2010, April). Tapping the inner teacher: Delivering high-impact learning through leader-led development (pp.1-14). Harvard Business School Publishing. Retrieved from 133 http://www.harvardbusiness.org/sites/default/files/15969_CL_WhitePaper_Teacher_April2010.pdf

Dealtry, R. (2002). How to configure the corporate university for success. Harborne, Birmingham: Dynamic SWOT Associates.

El-Tannir, A. (2002). The corporate university model for continuous learning, training and development. Education \& Training, 44(2), 76-81. doi 10.1108/00400910210419973

Freifeld, L. (2008, May). CU there. Training Magazine. Retrieved from www.trainingmag.com

Gerbman, R. (2000, February). Corporate universities 101. HR Magazine, 101-106.

Global Association of Corporate Universities and Academies (n.d.). Website. About us. Retrieved from: http://www.corporateuniversity.org.uk/acua/aboutgacua.htm

Global Council of Corporate Universities (n.d.). Website. Our history. Retrieved from: http://www. globalccu.com/globalccu-our-history.html

Greenberg, R. (1998 October). Corporate U. takes the job training field. Techniques Magazine: ACTEonline. Retrieved from http://www.thefreelibrary.com//print/PrintArticle.aspx?id=54117390

Herd, A., \& Alagaraja, M. (2016). Strategic human resource development: Conceptualization from the employee's perspective. In C. Hughes \& M. W. Gosney (Eds.) Bridging the Scholar-Practitioner Gap in Human Resources Development (Advances in Human Resources Management and Organizational Development) (pp.85-100). Hershey, PA: IGI Global.

Kiely, L. (2007). Corporate universities as shapers of culture. In M. Allen (Ed.), The next generation of corporate universities: Innovative approaches for developing and expanding organizational capabilities. San Francisco, CA: Wiley.

Lipp, D. (2013). Disney U: How Disney University develops the world's most engaged, loyal, and customercentric employees. New York, NY: McGraw Hill Education.

Meister, J. (1998). Corporate universities: Lessons in building a world-class workforce. Boston, MA: McGraw Hill.

Miller, V. A. (1996). The history of training. In Craig, R (ed.). The ASTD training and development handbook. New York, NY: McGraw-Hill.

Paton, R., Peters, G., Storey, J., \& Taylor, S. (2005). Handbook of corporate university development: Managing strategic learning initiative in public and private domains. Aldershot, UK: Gower.

Patten, M. L. (2009). Understanding research methods: An overview of the essentials. Glendale, CA: Pyrczak.

Prince, C., \& Beaver, G. (2002). Redefining the role of the corporate university: A UK perspective. Industry \& Higher Education, 16(4), 213-221. doi: 10.5367/000000002101296315

Prince, C., \& Stewart, J. (2002). Corporate universities: An analytical framework. Journal of Management Development, 21(10), 794-811. doi 10.1108/02621710210448057

Taylor, S. (2003, Winter). Corporate universities and redefinition of a medieval brand. International Higher Education. Retrieved from http;//www.bc.edu/bc_org/avp/soe/cihe/newsletter/news30/test002.htm

Taylor, S., \& Paton, R. (2002, July). Corporate universities: historical development, conceptual analysis. Observatory Reports, 7. Open University, Report, London, England: John Foster House. Retrieved from http://iedllit.open.ac.uk/icdlbrowsel.php?a=00014297

Toastmasters Website. (2015). Retrieved from https://www.toastmasters.org

University and Factory. (1920, May 9). Goodyear employees may study anything from the three R's to technical courses. New York Times (p.92). Retrieved from https://www.newspapers.com/ newspage/26760865/

Veldsman, T. (2004, August). The corporate university: Pinnacle of the learning organization. Management Today, 27-31. 
Walton, J. (2005). Would the real corporate university please stand up? Journal of European Industrial Training, 29(1), 7-20.

Wheeler, K., \& Clegg, E. (2005). The corporate university workbook: Launching the 21st century learning organization. San Francisco, CA: Jossey Bass.

Wills, K. V. (2001). From the classroom to the cubicle: Reading the rhetoric of the emerging corporate university. ERIC ED 463544 Retrieved from: http://eric.ed.gov/ERICWebPortal/custom/portlets/ recordDetails/detailmini.jsp?_nfpb=true\&_\&ERICExtSearch_SearchValue_0=ED463544\&ERICExtS earch_SearchType_0 =no\&accno=ED463544

Yin, R. (2009). Case study research: Design and methods. Los Angeles, CA: Sage.

\section{The Authors}

Dr. Gary Ewer is the Director of Education for Platt Electric Supply. He has worked at Platt for 33 years and has a passion to "help people reach their full potential". He and his team are responsible for supporting the talent development efforts of 1,290 employees, at 128 branch locations in nine western states through Platt University. Platt University is recognized as a highly successful corporate university and viewed by company leadership as providing a competitive advantage as Platt people are able to learn faster than the competition. He also serves on Rexel's Global Education Committee helping guide company training efforts in 35 countries. Platt Electric Supply is located in Beaverton, Oregon, USA. A company of Rexel Inc. Paris France

Darlene Russ-Eft, Ph.D., is Professor and Discipline Liaison of Adult and Higher Education in the College of Education at Oregon State University. She works with senior leaders and practitioners in the doctoral higher education leadership concentration and in the adult education masters' programme. Her recent research focuses on identifying potential performance indicator systems for foundations, and she continues to undertake evaluations of learning interventions in educational and in workplace settings. Dr. Russ-Eft is a past president for the Academy of Human Resource Development (AHRD), a past director of the International Board of Standards for Training, Performance, and Instruction (ibstpiR) and a past board member of the American Evaluation Association. She is a past editor of the Human Resource Development Quarterly. She received the 1996 Editor of the Year Award from Times Mirror, the AHRD Outstanding Scholar Award, and the Outstanding Research Article Award from ASTD (now Association for Talent Development, ATD). 